\title{
AVALIAÇÃO DA LIBERAÇÃO DE ELEMENTOS TRAÇO EM SOLOS TRATADOS COM XISTO RETORTADO
}

\author{
Jeniffer V. dos Santos ${ }^{a}$, Rafael J. B. De Presbiteris ${ }^{a}$, Vanessa C. G. dos Santos ${ }^{\mathrm{a}}$, Marco T. Grassi ${ }^{\mathrm{a}}$, Iara Messerschmidt ${ }^{\mathrm{a}}$, \\ Betânia F. Pereira ${ }^{a}$, Rosane Martinazzo ${ }^{\mathrm{b}}$ e Gilberto Abate ${ }^{\mathrm{a}, *}$ \\ a'Departamento de Química, Universidade Federal do Paraná, Centro Politécnico, 81531-990, Curitiba - PR, Brasil

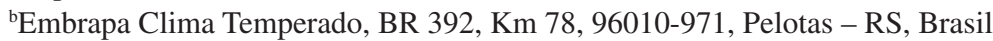

Recebido em 10/08/2016; aceito em 30/01/2017; publicado na web em 24/03/2017

\begin{abstract}
EVALUATION OF TRACE ELEMENTS RELEASING FROM SOILS TREATED WITH RETORTED OIL SHALE. Soils that had received successive applications of retorted oil shale (ROS) in an experiment under field conditions were used in this study, aiming to evaluate the availability of trace elements. In the batch tests, we observed that toxic elements present in the ROS are not desorbed from the matrix in significant amounts to contaminate soil and groundwater. The element Ca represents the greatest nutrient contribution, which has high mobility and ease release into the soil solution. Concerning the results obtained from the soil extracts analysis; we observed that the undesirable elements released into the extracts are not directly related to the presence of ROS in the soil samples. Comparing the behavior of soil samples with and without ROS it is possible to infer that many of the trace elements are derived from soil constituents, from previous fertilizer and pesticides applications. The study suggested that the ROS can be used as a soil conditioner for agricultural purposes without adding harmful elements to the environment.
\end{abstract}

Keywords: soils; trace elements; retorted oil shale.

\section{INTRODUÇÃO}

O folhelho pirobetuminoso (xisto) é uma rocha sedimentar rica em querogênio, que é um composto orgânico de composição indefinida, gerado pela ação química e de microrganismos sobre a matéria orgânica ao longo de milhões de anos. ${ }^{1} \mathrm{O}$ Brasil possui a segunda maior reserva de xisto no mundo, sendo os Estados Unidos detentor das maiores reservas mundiais, ${ }^{1,2}$ além de outros países que merecem destaque como Austrália, Canadá, China, Estônia, Itália, Jordânia, Marrocos, Rússia e Zaire. ${ }^{3}$ Em São Mateus do Sul, no estado do Paraná, é explorada a extração de xisto da mais importante reserva de xisto do Brasil, a Formação Irati, a qual abrange também os estados de Mato Grosso do Sul, Goiás, São Paulo, Santa Catarina e Rio Grande do Sul. ${ }^{3}$ A Unidade de Negócios da Industrialização do Xisto realiza a mineração e o processamento do xisto extraído neste local. O processamento do xisto produz óleo e gás em condições de alta temperatura e alta pressão, além de outros subprodutos, sendo um deles o xisto retortado (XR) produzido em grandes quantidades, representando cerca de 80 a $90 \%$ da quantidade de matéria prima inicial do processo. ${ }^{1}$

O XR é uma matriz dependente de sua origem e do processo de extração de óleo e gás, e pode conter compostos orgânicos e elementos traços indesejáveis ao meio ambiente. A composição química e as características do XR têm sido objeto de estudo de vários países, variando conforme a região de origem. ${ }^{1,4-10} \mathrm{Na}$ matriz do XR estão presentes minerais tais como quartzo, feldspatos, argilas (principalmente ilita e clorita), carbonatos (calcita e dolomita), pirita e outros minerais. ${ }^{11-13}$ Outros elementos químicos também estão presentes no XR como $\mathrm{Fe}, \mathrm{Al}, \mathrm{Mg}, \mathrm{Ca}, \mathrm{K}$ e P, em quantidades majoritárias, além de elementos em menores proporções como $\mathrm{Mn}, \mathrm{Zn}, \mathrm{Ba}, \mathrm{Pb}$, $\mathrm{Mo}, \mathrm{Cu}, \mathrm{Ni}, \mathrm{Cr}$, $\mathrm{Co}$ e $\mathrm{Cd}$, entre outros. As quantidades relativas de cada elemento dependem da localidade da mina, das quantidades de elementos no xisto cru, composição do querogênio e tecnologia empregada no beneficiamento. ${ }^{6,8,14,15}$

O XR tem sido reaproveitado na indústria de cerâmica e cimento, ${ }^{3}$ estudado como sorvente para íons $\mathrm{Pb}^{2+}, 1,16$ e utilizado para produção

\footnotetext{
*e-mail: gilberto@quimica.ufpr.br
}

de energia. ${ }^{17}$ Aspectos como a perda de nutrientes por conta da lixiviação ocasionada pelas chuvas, culturas que absorvem determinados nutrientes em maiores quantidades, falta de rotação de culturas ou mesmo atividades antrópicas ocasionam a necessidade de adição de nutrientes adequados ao solo. ${ }^{18-20}$ Mais recentemente, estudos têm sido dedicados para a avaliação do emprego do XR como condicionador de solos em decorrência da sua elevada porosidade e capacidade de troca catiônica (CTC), composição mineral contendo macro e micronutrientes, bem como os possíveis efeitos no crescimento das plantas. Pereira e Vitti, ${ }^{21}$ aplicaram 0, 3, 6, 9 e $12 \mathrm{t} \mathrm{de} \mathrm{XR} \mathrm{ha}^{-1}$ ao solo e avaliaram os efeitos no plantio de tomates. Foi constatado aumento nos teores de $\mathrm{S}, \mathrm{Ca}$ e $\mathrm{Mg}$ nas amostras de solos, ao passo que para o C e micronutrientes não foram observadas mudanças significativas nas concentrações, embora um aumento expressivo tenha sido observado para o Mo. Também não foram constatados aumentos significativos nas concentrações de P, K, Ca e Mg e de micronutrientes em função das diferentes doses de XR aplicadas nas amostras de folhas, ao passo que para o $\mathrm{Si}$, um aumento significativo foi observado. Em outro estudo, foi constatado que a adição de quantidades crescentes de XR favoreceu a fixação de carbono proveniente de folhas e talos de soja em solos. ${ }^{22}$ Cabe ressaltar também que a presença de XR em solo reduziu a emissão de $\mathrm{CO}_{2}$ e não influenciou negativamente na atividade microbiana e enzimática do solo, pelo menos até o limite de 3 ton de XR ha ${ }^{-1}$ de solo. ${ }^{23}$

Apesar da possibilidade de uso do XR na agricultura, é importante levar em consideração a presença de compostos orgânicos indesejáveis que podem estar presentes no XR. Nicolini et al..$^{9}$ constataram a presença de oito diferentes hidrocarbonetos policíclicos aromáticos (HPA), dentre os dezesseis HPA estabelecidos como poluentes prioritários, nas amostras coletadas no interior das pilhas de XR, ao passo que para amostras de XR coletadas na superfície das pilhas, as concentrações observadas foram comparativamente inferiores. Dessa forma, os autores sugerem o uso de XR disposto em camadas rasas, a fim de favorecer a degradação dos HPA. Outros compostos tóxicos que podem ser liberados no solo são os íons provenientes de metais tóxicos, entretanto, poucos estudos têm sido direcionados a esse assunto. Pereira e Vitti ${ }^{21}$ propuseram o uso de XR em solo e 
estudaram a liberação de íons de $\mathrm{Ni}, \mathrm{Cd}, \mathrm{Cr}, \mathrm{Pb}, \mathrm{Co}, \mathrm{Ti}, \mathrm{Ba}, \mathrm{V}, \mathrm{Cu}$ e Mo em solo e, de modo geral, não foram observadas modificações nas concentrações de diversos íons metálicos indesejáveis em função do aumento nas quantidades de XR, em comparação com solo testemunha, exceto em um dos experimentos para o titânio. Além disso, houve a diminuição do teor de bário em decorrência da presença de sulfato proveniente do próprio XR. De acordo com esses autores, a baixa concentração de metais tóxicos no XR propicia o seu uso como condicionador de solos, sem causar riscos. Adamson et al. ${ }^{24}$ avaliaram a liberação de íons dos metais $\mathrm{Cd}, \mathrm{Cr}, \mathrm{Ni}, \mathrm{Pb}$ e $\mathrm{Zn}$, pela aplicação de cinzas de XR em duas amostras de solos. De acordo com esse estudo, os íons de $\mathrm{Ni}$, $\mathrm{Cr}$ e $\mathrm{Zn}$ foram aqueles de maior mobilidade; contudo, de acordo com os autores, as concentrações dos íons metálicos nos lixiviados foram bem abaixo dos padrões legislados, sendo o processo de lixiviação dependente do tipo de solo e das cinzas, além das condições de lixiviação.

De acordo com o que foi exposto, há a possibilidade de emprego do XR como insumo agrícola, porém, é preciso avaliar o potencial de contaminação do solo por elementos tóxicos. Dessa forma, o foco do presente trabalho foi investigar a possível contaminação por diversos elementos para o solo tratado com adições crescentes de XR. Foi estudada a liberação de diversos íons nutrientes ou tóxicos, em batelada, sendo os resultados obtidos confrontados com os valores orientadores em águas subterrâneas da legislação do Conselho Nacional do Meio Ambiente (CONAMA) em sua Resolução ${ }^{\circ}$ 420.25

\section{PARTE EXPERIMENTAL}

\section{Área de estudo e amostragem}

O estudo foi realizado na área experimental da Universidade Federal de Santa Maria - UFSM, no Rio Grande do Sul. O solo em que foram conduzidos os experimentos foi caracterizado como argissolo vermelho distrófico arênico. Suas principais características, segundo o Sistema Brasileiro de Classificação de Solos, ${ }^{26}$ são textura arenosa desde a superfície até um mínimo de $50 \mathrm{~cm}$ e um máximo de $100 \mathrm{~cm}$ de profundidade e horizonte B textural (conteúdo de argila maior em relação ao horizonte A) dentro de $200 \mathrm{~cm}$ do perfil do solo.

Foi utilizado XR originário da unidade de beneficiamento de xisto localizada em São Mateus do Sul - PR, com tamanho de partícula menor que $0,30 \mathrm{~mm} \cdot{ }^{23} \mathrm{O}$ solo estudado recebeu diferentes tratamentos em campo, com aplicação superficial de doses crescentes de XR, lançado em superfície, além da adubação de base (NPK - fontes de nitrogênio, fósforo e potássio). O experimento foi instalado em 2009 , sendo que as coletas de solo foram realizadas em Novembro de 2011, Junho de 2012 e Janeiro de 2013, nas profundidades de $0-5 \mathrm{~cm}$ e de $5-10 \mathrm{~cm}$.

O procedimento de coleta foi feito com abertura de covas com uma pá, separando-se os solos de cada profundidade. A coleta para cada tratamento foi feita em quadruplicata e as frações coletadas foram homogeneizadas para compor uma amostra representativa, totalizando cerca de 5,0 kg de solo. Em seguida as amostras foram homogeneizadas e peneiradas com peneira de $2 \mathrm{~mm}$. As amostras foram secas ao ar, reservadas em sacos de polietileno, etiquetadas e transportadas para o Departamento de Química da Universidade Federal do Paraná. As amostras foram quarteadas para a realização dos experimentos em batelada, a partir de 1,0 kg de solo até se obter a massa desejada para o experimento $(2 \mathrm{~g})$, separando-se as triplicatas para o experimento em batelada. Deste modo, todas as granulometrias que compõem a amostra foram repartidas igualmente, compondo uma amostra representativa. A Tabela 1 apresenta as doses anuais de XR aplicadas em cada um dos tratamentos e, com base nisso, a quantidade de XR acumulado no momento de cada uma das três coletas.

Cabe informar que os valores citados na Tabela 1 foram definidos com base em estudos anteriores do grupo de pesquisa vinculado ao Projeto Xisto Agrícola (Termo de Cooperação entre Embrapa Clima Temperado, PETROBRAS/SIX e FAPEG). Há uma recomendação de uma dose anual de $500 \mathrm{~kg} \mathrm{ha}^{-1}$, sendo que no presente estudo foram aplicadas quantidades bem superiores a esse valor (conforme Tabela 1), para se ter o experimento em condições extremas de aplicação de XR.

\section{Equipamentos, reagentes e soluções}

As amostras de solo e de XR foram previamente caracterizadas por difração de raio $\mathrm{X}$ (XRD), sendo utilizado um equipamento da marca Shimadzu, modelo XRD-6000, utilizando radiação $\mathrm{Cu} \mathrm{K} \alpha$ $(\lambda=1,5418 \AA$ ) com parâmetros de $40 \mathrm{kV}$ e $40 \mathrm{~mA}$. Os ângulos de varredura foram entre 10 e $80^{\circ}(2 \theta)$ com velocidade de $2^{\circ} \mathrm{min}^{-1}$. Também foram determinados alguns elementos por fluorescência de raio $\mathrm{X}(\mathrm{XRF})$ empregando um equipamento da marca Panalytical, modelo Axios Max.

Para as determinações dos elementos foi utilizado um Espectrômetro de Emissão Ótica com Plasma Indutivamente Acoplado (ICP OES) da marca Thermo Scientific, modelo iCAP 6500. As medidas de $\mathrm{pH}$ foram efetuadas utilizando um $\mathrm{pHmetro}$ marca MS Tecnopon, modelo MPA 210 previamente calibrado com soluções tampão de pH 7,00 e 4,00, ao passo que as determinações de condutividade foram feitas empregando um condutivímetro da marca MS Tecnopon, modelo MCA 150, calibrado com uma solução de $\mathrm{KCl} \mathrm{0,01} \mathrm{mol} \mathrm{L}^{-1}$.

A água empregada em todos os experimentos, preparo de soluções e enxágue de vidrarias foi obtida por sistema de osmose reversa (Marca Quimis, Q842-210) seguida da purificação em um equipamento da marca Millipore modelo Simplicity, dotado de lâmpada UV. Esse sistema proporcionou água com resistividade superior a $18 \mathrm{M} \Omega \mathrm{cm}$, sendo essa água designada no presente trabalho como água tipo 1 .

Tabela 1. Amostras coletadas em Santa Maria (RS) e os diferentes tratamentos aplicados em campo

\begin{tabular}{|c|c|c|c|c|c|c|c|}
\hline \multirow{3}{*}{ Tratamento } & \multicolumn{4}{|c|}{ XR (aplicado na superfície) $\left(\mathrm{kg} \mathrm{ha}^{-1}\right)$} & \multirow{2}{*}{\multicolumn{3}{|c|}{ Adubação (kg ha $\left.{ }^{-1}\right)$}} \\
\hline & \multirow{2}{*}{$\begin{array}{l}\text { Doses anuais } \\
\text { aplicadas }\end{array}$} & \multirow{2}{*}{$\begin{array}{c}1^{\mathrm{a}} \text { coleta Novembro/2011 } \\
\text { XR acumulado }\end{array}$} & \multirow{2}{*}{$\begin{array}{c}2^{\mathrm{a}} \text { coleta Junho/2012 } \\
\text { XR acumulado } \\
\end{array}$} & \multirow{2}{*}{$\frac{3^{\text {a }} \text { coleta Janeiro/2013 }}{\text { XR acumulado }}$} & & & \\
\hline & & & & & $\mathrm{N}$ & $\mathrm{P}_{2} \mathrm{O}_{5}$ & $\mathrm{~K}_{2} \mathrm{O}$ \\
\hline $\mathrm{T} 1$ & 0 & 0 & 0 & 0 & 100 & 120 & 90 \\
\hline $\mathrm{T} 2$ & 750 & 1500 & 2250 & 2250 & 100 & 120 & 90 \\
\hline $\mathrm{T} 3$ & 1500 & 3000 & 4500 & 4500 & 100 & 120 & 90 \\
\hline $\mathrm{T} 4$ & 3000 & 6000 & 9000 & 9000 & 100 & 120 & 90 \\
\hline T5 & 0 & 0 & 0 & 0 & 0 & 0 & 0 \\
\hline T6 & 1500 & 3000 & 4500 & 4500 & 0 & 0 & 0 \\
\hline
\end{tabular}


As soluções padrão dos elementos estudados foram preparadas a partir de sais solúveis na forma de nitratos, ou empregando soluções padrão multi-elementares para ICP OES. Os sais ou as soluções foram adquiridos de fornecedores como Merck, Sigma-Aldrich, Carlo Erba ou de qualidade similar, bem como o ácido nítrico, ácido acético e peróxido de hidrogênio. Toda a vidraria, tubos de centrífuga e frascos plásticos empregados no presente trabalho foram lavados com água e detergente Extran neutro, e após o enxágue foram mantidos por pelo menos $24 \mathrm{~h}$ em solução de ácido nítrico 5\%, e novamente enxaguados com água tipo 1.

Os experimentos de dessorção foram conduzidos a $25^{\circ} \mathrm{C}$, sendo utilizada uma incubadora refrigerada com agitação orbital, da marca Tecnal, modelo TE-421. Outros equipamentos e materiais auxiliares como centrífuga, refrigerador $\left(4^{\circ} \mathrm{C}\right)$, estufa e micropipetas com volumes variáveis também foram utilizados.

\section{Procedimento de lixiviação e de digestão do XR}

Foram realizados experimentos de dessorção por batelada em água tipo 1, com as amostras T1 a T6 (Tabela 1), com base na norma DIN 38914 (S4) ${ }^{27}$ de acordo com Delay et al. ${ }^{28}$ Em torno de 2,0 g $( \pm 0,1 \mathrm{mg})$ das amostras (base seca) foram acondicionadas em tubos plásticos de centrífuga, adicionando-se $40,0 \mathrm{~mL}$ de água tipo 1 , sendo os tubos mantidos sob agitação por $24 \mathrm{~h}$ a $25^{\circ} \mathrm{C}$. Também foram conduzidos experimentos similares, porém, empregando ácido acético (pH 5,00 \pm 0,05), segundo a norma brasileira da ABNT NBR 10005 (procedimento para obtenção de extrato lixiviado de resíduos sólidos), ${ }^{29}$ exceto que, nesse caso, foi utilizado tempo de agitação de 18 h. Após o período de agitação as amostras foram centrifugadas por 20 minutos, a $3000 \mathrm{rpm}$. Nas fases sobrenadantes obtidas pelos extratos em água tipo 1 foram determinados os valores de $\mathrm{pH}$ e condutividade. Todas as fases aquosas foram acondicionadas em frascos plásticos de polietileno em meio de ácido nítrico $1,0 \%$ (v/v) e mantidas a $4{ }^{\circ} \mathrm{C}$ até o momento de efetuar as determinações. Todos os experimentos foram conduzidos em triplicata.

Foi realizada a digestão da amostra de XR, sendo utilizada uma massa de $1,0 \mathrm{~g}$ em $\mathrm{HNO}_{3}$ concentrado e $\mathrm{H}_{2} \mathrm{O}_{2} 30 \%$ com base na norma da Environmental Protection Agency - EPA 3050B. ${ }^{30}$ Os extratos obtidos foram diluídos até $100 \mathrm{~mL}$ com água tipo 1 e armazenados como os demais extratos para a determinação dos elementos de interesse. Esse procedimento de digestão foi conduzido apenas para a amostra de XR e não para as amostras de solo, com o intuito de determinar o teor dos elementos no XR. Experimentos de dessorção em meio aquoso também foram conduzidos para o XR, de modo análogo para as amostras de solo.

\section{Determinação dos elementos por ICP OES}

As curvas analíticas por ICP OES foram estabelecidas com sete diferentes concentrações para cada elemento de interesse em faixas de concentração de acordo com a necessidade, respeitando o LQ de cada um dos elementos. A faixa de concentração para as curvas analíticas da maioria dos elementos foi entre $1,0 \mu \mathrm{g} \mathrm{L}^{-1} \mathrm{e}$ $1000 \mu \mathrm{g} \mathrm{L}{ }^{-1}$. Um estudo prévio de recuperação foi efetuado, sendo adicionado em amostras de extrato de solo $100 \mu \mathrm{g} \mathrm{L}^{-1}$ de cada um dos elementos estudados.

As concentrações dos elementos nos extratos obtidos em meio de água tipo 1, ácido acético e proveniente da digestão do XR foram determinadas com base nas referidas curvas analíticas por ICP OES. Para a determinação de Hg por ICP OES foi utilizado o método de geração de vapor a frio proposto por dos Santos et $a l .{ }^{31}$ e para quantificar o As foi utilizado o método de geração de hidretos. ${ }^{32}$

\section{RESULTADOS E DISCUSSÃO}

\section{Caracterização das amostras de solos e de XR}

As amostras de solos da primeira coleta e na profundidade de $0-5 \mathrm{~cm}$, e as amostras de XR foram inicialmente caracterizadas por XRD, sendo constatada uma constituição majoritária de quartzo para todas as amostras de solo. Também foram observados alguns picos referentes à hematita $\left(\mathrm{Fe}_{2} \mathrm{O}_{3}\right)$, berlinita $\left(\mathrm{AlO}_{4} \mathrm{P}\right)$, brucita $\left(\mathrm{Mg}(\mathrm{OH})_{2}\right)$ e rutilo $\left(\mathrm{TiO}_{2}\right)$, cujas intensidades dos picos são reduzidas pela presença do quartzo $\left(\mathrm{SiO}_{2}\right){ }^{33,34} \mathrm{O}$ difratograma do $\mathrm{XR}$ apresentou picos referentes à albita $\left(\mathrm{NaAlSi}_{3} \mathrm{O}_{8}\right)$, ortoclásio $\left(\mathrm{KAlSi}_{3} \mathrm{O}_{8}\right)$ e carbonatos de cálcio e magnésio, além de picos característicos de quartzo.

Alguns elementos foram determinados por XRF, sendo observados valores similares entre as amostras de solo (T1 - T6) e assim foram calculados os valores médios. Nesse caso foram utilizadas somente as amostras de solo da $1^{\text {a }}$ coleta (Tabela 1). Esses resultados bem como os resultados obtidos para o XR, todos expressos na forma de óxidos, são apresentados na Tabela 2. Além disso, são mostrados dois resultados da literatura para o XR, também da região de Irati, para fins de comparação.

Tabela 2. Composição percentual das amostras de solos tratados ( $1^{\mathrm{a}}$ coleta, $\% \mathrm{~m} \mathrm{~m}^{-1}$, média \pm desvio padrão, $n=6$ ) e do XR por XRF

\begin{tabular}{lcccc}
\hline \multirow{2}{*}{ Óxidos } & Solos & $\begin{array}{c}\mathrm{XR} \\
\text { (presente estudo) }\end{array}$ & \multicolumn{2}{c}{$\begin{array}{c}\text { XR } \\
\text { (literatura) }\end{array}$} \\
\cline { 2 - 5 } & $\begin{array}{c}\text { Valor médio } \\
\mathrm{T} 1-\mathrm{T} 6\end{array}$ & $(\%)$ & $(\%)^{1}$ & $(\%)^{9}$ \\
\hline $\mathrm{SiO}_{2}$ & $90,0 \pm 0,4$ & 48,0 & 51,94 & $44,4-50,7$ \\
$\mathrm{Al}_{2} \mathrm{O}_{3}$ & $3,22 \pm 0,04$ & 11,1 & 16,9 & $10,2-11,7$ \\
$\mathrm{Fe}_{2} \mathrm{O}_{3}$ & $2,47 \pm 0,08$ & 9,2 & 6,05 & $5,0-6,5$ \\
$\mathrm{TiO}_{2}$ & $0,93 \pm 0,03$ & 0,7 & 0,38 & $0,4-0,5$ \\
$\mathrm{~K}_{2} \mathrm{O}$ & $0,22 \pm 0,03$ & 2,6 & 1,97 & $1,8-2,0$ \\
$\mathrm{CO}_{2}$ & $2,78 \pm 0,05$ & 15,6 & - & - \\
$\mathrm{MgO}$ & $\mathrm{ND}^{\mathrm{a}}$ & 2,1 & 1,72 & $1,1-1,5$ \\
$\mathrm{CaO}^{\mathrm{n}}$ & $\mathrm{ND}^{\mathrm{a}}$ & 2,7 & 0,08 & $0,6-3,7$ \\
$\mathrm{Na}_{2} \mathrm{O}$ & $\mathrm{ND}^{\mathrm{a}}$ & 1,4 & 1,73 & $0,7-1,0$ \\
$\mathrm{P}_{2} \mathrm{O}_{5}$ & $\mathrm{ND}^{\mathrm{a}}$ & 0,3 & - & - \\
$\mathrm{SO}_{3}$ & $\mathrm{ND}^{\mathrm{a}}$ & 6,0 & - & $4,4-7,2$ \\
\hline
\end{tabular}

${ }^{a} \mathrm{ND}$ : Não detectado.

Com base nas determinações por XRF, foi observado um elevado teor de $\mathrm{SiO}_{2}$ para as amostras de solo de $90,0 \%$ e de $48 \%$ para o XR, estando esse valor para o XR em boa concordância com a literatura para amostras procedentes da mesma região e de diferentes períodos. ${ }^{1,9}$ De modo geral, pode-se constatar uma boa similaridade entre os resultados deste trabalho em comparação com aqueles da literatura para a maioria dos elementos na forma de óxidos. Os resultados obtidos por XRF mostraram teores mais elevados de alguns elementos em relação ao solo estudado, tais como $\mathrm{Al}, \mathrm{Fe}, \mathrm{K}, \mathrm{C}, \mathrm{Mg}, \mathrm{Ca}, \mathrm{Na}, \mathrm{P}$ e $\mathrm{S}$, sugerindo a possibilidade de liberação de tais elementos no solo.

Foram determinados diversos parâmetros físico-químicos para as amostras de solo de acordo com os resultados mostrados na Tabela 3, sendo nesse caso avaliadas as amostras da primeira coleta de solos.

De modo geral, não foram constatadas diferenças significativas entre os tratamentos feitos em campo (T1 - T6). Isso é indicativo que o XR não causou qualquer modificação nas amostras de solo. Apesar disso, cabe salientar que o XR apresentou maior valor de $\mathrm{pH}$ em relação às amostras de solo, o que também foi observado por 
Tabela 3. Resultados das determinações de parâmetros agronômicos para as amostras de solos e para o XR $\left(1^{\mathrm{a}}\right.$ coleta, média \pm desvio padrão, $n=3$ )

\begin{tabular}{|c|c|c|c|c|c|c|c|c|c|}
\hline \multirow{2}{*}{ Amostra } & \multirow{2}{*}{$\mathrm{pH}^{\mathrm{a}}$} & \multirow{2}{*}{$\mathrm{pH} \mathrm{SMP}$} & \multirow{2}{*}{$\begin{array}{c}\mathrm{P} \\
\left(\mathrm{mg} \mathrm{kg}^{-1}\right)\end{array}$} & \multirow{2}{*}{$\begin{array}{c}\mathrm{MO}^{\mathrm{c}} \\
\left(\mathrm{g} \mathrm{kg}^{-1}\right)\end{array}$} & $\mathrm{Al}$ & $\mathrm{H}+\mathrm{Al}$ & $\mathrm{Ca}$ & $\mathrm{Mg}$ & $\mathrm{K}$ \\
\hline & & & & & \multicolumn{5}{|c|}{$\left(\right.$ mmolc $\left.\mathrm{kg}^{-1}\right)$} \\
\hline $\mathrm{T} 1$ & $5,07 \pm 0,06$ & $6,27 \pm 0,06$ & $46,6 \pm 0,2$ & $31,3 \pm 0,6$ & $\mathrm{ND}^{\mathrm{d}}$ & $30 \pm 1$ & $16,7 \pm 0,4$ & $8,8 \pm 0,7$ & $2,28 \pm 0,01$ \\
\hline $\mathrm{T} 2$ & $4,90 \pm 0,01$ & $6,20 \pm 0,01$ & $35,93 \pm 0,06$ & $29,1 \pm 0,3$ & $0,080 \pm 0,001$ & $34,4 \pm 0,1$ & $19,5 \pm 0,4$ & $10,7 \pm 0,5$ & $2,19 \pm 0,05$ \\
\hline $\mathrm{T} 3$ & $4,93 \pm 0,06$ & $6,17 \pm 0,06$ & $38,4 \pm 0,4$ & $29,4 \pm 0,4$ & $0,083 \pm 0,001$ & $37 \pm 1$ & $21,1 \pm 2,7$ & $10,6 \pm 0,5$ & $2,4 \pm 0,1$ \\
\hline $\mathrm{T} 4$ & $4,90 \pm 0,01$ & $6,27 \pm 0,06$ & $42,1 \pm 0,4$ & $34,3 \pm 0,4$ & $0,081 \pm 0,001$ & $33 \pm 1$ & $20,4 \pm 1,9$ & $9,7 \pm 0,8$ & $2,10 \pm 0,01$ \\
\hline T5 & $4,90 \pm 0,01$ & $6,20 \pm 0,01$ & $30,1 \pm 0,2$ & $33,2 \pm 0,2$ & $0,077 \pm 0,001$ & $33,1 \pm 0,1$ & $15,4 \pm 0,8$ & $9,0 \pm 0,4$ & $2,05 \pm 0,04$ \\
\hline T6 & $4,83 \pm 0,06$ & $6,07 \pm 0,06$ & $26,7 \pm 0,2$ & $35,8 \pm 0,3$ & $0,083 \pm 0,001$ & $39 \pm 2$ & $18,7 \pm 0,5$ & $9,09 \pm 0,01$ & $2,12 \pm 0,05$ \\
\hline XR & $5,83 \pm 0,06$ & $6,97 \pm 0,06$ & $155 \pm 3$ & $71,0 \pm 0,1$ & $\mathrm{ND}^{\mathrm{d}}$ & $30,4 \pm 0,7$ & $135 \pm 56$ & $31 \pm 11$ & $5,7 \pm 0,3$ \\
\hline
\end{tabular}

${ }^{\mathrm{a}} \mathrm{pH}$ em meio de $\mathrm{CaCl}_{2}$ 0,01 mol L-1; ${ }^{\mathrm{b}} \mathrm{SMP}$ : Shoemaker-McLean-Pratt; ${ }^{\mathrm{c}} \mathrm{MO}$ : matéria orgânica; ${ }^{\mathrm{d}} \mathrm{ND}$ : Não detectado.

Pereira e Vitti, ${ }^{21}$ além de maiores conteúdos de nutrientes e matéria orgânica (Tabela 3). É possível que o processo de dessorção de elementos provenientes do XR não seja significativo a ponto de ser mensurável, não sendo suficiente a quantidade de XR incorporada ao solo para a liberação dos elementos estudados. Todavia, esses resultados superiores em relação às amostras de solo, aliado aos maiores teores observados para alguns elementos por XRF, sugerem que o XR possui potencial para o fornecimento de nutrientes ao solo. Para o Ca foram observados teores significativamente maiores para as amostras que receberam $\mathrm{XR}(\mathrm{T} 2, \mathrm{~T} 3, \mathrm{~T} 4, \mathrm{~T} 6)$.

\section{Determinação de pH e condutividade elétrica nos extratos}

Antes da determinação da concentração de íons metálicos foram efetuadas medidas de $\mathrm{pH}$ e condutividade elétrica (CE) dos extratos obtidos em água tipo 1. Para a determinação desses dois parâmetros as três coletas de solos foram avaliadas.

Nos extratos obtidos a partir dos experimentos em água tipo 1 foram verificados valores muito similares de $\mathrm{pH}$ para as três coletas efetuadas, sendo o valor médio para de $\mathrm{pH}=6,2 \pm 0,3(0-5 \mathrm{~cm}) \mathrm{e}$ de $5,9 \pm 0,1(5-10 \mathrm{~cm})$ ao passo que para o extrato de $\mathrm{XR}$ o $\mathrm{pH}$ verificado foi de 6,9, embora de acordo com a literatura, o XR apresenta características alcalinas. ${ }^{21,35}$ Apesar do valor de $\mathrm{pH}$ mais elevado para o extrato de XR, não foram constatadas tendências de elevação nos valores de $\mathrm{pH}$ em função das adições de XR nos solos, para as três coletas, o que está concordante com a literatura. ${ }^{21}$

A medida de CE de extratos de solo é importante, pois é um indicativo do aumento ou diminuição do teor de sais dissolvidos nos solos. ${ }^{26,36}$ De modo geral, os valores de CE se situaram entre 15 e 40 $\mu \mathrm{S} \mathrm{cm} \mathrm{cm}^{-1}$, para as duas profundidades nas coletas 1 e 3 . Na coleta 2, um comportamento bem similar foi observado, embora dois valores mais elevados de $75 \mu \mathrm{S} \mathrm{cm}^{-1}$ e $58 \mu \mathrm{S} \mathrm{cm}^{-1}$ foram constatados para T3 e T6, respectivamente, para a profundidade de $5-10 \mathrm{~cm}$. Apesar disso, é provável que isso não esteja relacionado com a presença de $\mathrm{XR}$, visto que para T4, que teve a maior adição de XR, não foram verificados valores mais elevados em nenhuma das três coletas para as duas profundidades. Dessa forma, mesmo com teores mais elevados de alguns elementos no XR, pode-se inferir que esses elementos não foram liberados, pelo menos em $24 \mathrm{~h}$, ou as quantidades liberadas não foram suficientes para causar uma alteração perceptível nos valores de $\mathrm{CE}$.

\section{Determinação de Al, Ca, Fe, Mg, As, Ba, Cd, Co, Cr, Cu, Hg, $\mathrm{Mn}, \mathrm{Mo}, \mathrm{Ni}, \mathrm{Pb}$ e $\mathrm{Zn}$}

Inicialmente foi avaliada a linearidade do método empregado, que é determinada pelo coeficiente de determinação $\left(r^{2}\right)$, o qual deve ser superior a 0,90 , segundo a literatura. ${ }^{37}$ Foi observada boa linearidade entre as curvas avaliadas, com $r^{2}$ variando de 0,9957 até 0,9999. Testes de hipóteses de $\mathrm{t}$ e $\mathrm{F}$ foram realizados para avaliar a significância da regressão e do desvio da linearidade. Valores bastante elevados de $\mathrm{F}$ confirmaram uma regressão significativa na faixa de concentração estudada. ${ }^{38}$ Os perfis dos gráficos de resíduos de regressão demonstraram que não houve tendências de heteroscedasticidade ou de desvio de linearidade.

Os valores de limite de detecção (LD) e limite de quantificação (LQ) foram calculados pelas expressões: $\mathrm{LD}=3 s / \mathrm{S}$ e $\mathrm{LQ}=10 \mathrm{~s} / \mathrm{S}$, sendo $s$ a estimativa do desvio padrão de dez provas em branco e $S$ é a inclinação da curva analítica. Os valores de LD se situaram entre $0,003 \mu \mathrm{g} \mathrm{L}{ }^{-1}$ e $4,3 \mu \mathrm{g} \mathrm{L}^{-1}$ para $\mathrm{Mn}$ e $\mathrm{Al}$, respectivamente, ao passo que para o LQ, valores entre $0,01 \mu \mathrm{g} \mathrm{L}^{-1}$ e $14,2 \mu \mathrm{g} \mathrm{L}^{-1}$ foram verificados para esses mesmos elementos. No caso do $\mathrm{Pb}$, o limite máximo é de $10 \mu \mathrm{g} \mathrm{L}{ }^{-1}$ para águas subterrâneas, ${ }^{25}$ sendo esse o único elemento dentre os que foram estudados no presente trabalho que o LQ verificado $\left(12,3 \mu \mathrm{g} \mathrm{L}^{-1}\right)$ foi superior ao valor legislado.

Foram também realizados testes de recuperação com adição de padrão dos elementos na concentração de $100 \mu \mathrm{g} \mathrm{L} \mathrm{L}^{-1}$ às amostras de extratos de solo. Esses experimentos foram conduzidos visando verificar se poderia haver interferência na etapa de quantificação, em decorrência dos extratos obtidos pelas matrizes de solo. Foram constatados valores de recuperação entre $82,7 \%(\mathrm{~Pb})$ e $118,1 \%(\mathrm{Cu})$ e, além disso, a maioria dos valores de recuperação se situaram muito próximo de $100 \%$, sugerindo não haver interferência significativa, o que permitiu a continuidade dos estudos posteriores.

\section{Teores dos elementos no XR e avaliação dos extratos de XR}

A Tabela 4 apresenta os teores dos elementos contidos no XR, e as concentrações nos extratos obtidos a partir do XR em meio aquoso, além da comparação com os valores máximos permitidos pelo CONAMA ${ }^{25}$ considerando águas subterrâneas e o fator de mobilidade (FM). Cabe salientar que essa avaliação foi conduzida apenas para o XR, na ausência das amostras de solo, visando verificar se a presença dos elementos de interesse nos extratos de solo poderia estar relacionada com o XR.

Como pode ser observado na Tabela 4, tanto no XR quanto no extrato da batelada do XR não foram detectados os elementos $\mathrm{Hg}$ e As, que são altamente tóxicos, conforme observado por Maranhão et al..$^{39}$ Apesar de ter sido determinado no XR, a concentração de Cd no extrato da batelada ficou abaixo do LQ, indicando a baixa mobilidade desse elemento a partir da matriz do XR. Não foi constatada a presença de Co no XR, e em consequência não foi detectado no extrato em meio aquoso. O XR apresentou altos teores de Al, Fe, Ca e Mg, o que está em concordância com os resultados obtidos por XRF 
Tabela 4. Teor dos elementos no XR, e concentração nos extratos do XR em meio aquoso, (média \pm desvio padrão, $n=3$ ) limites do CONAMA, LQ e FM

\begin{tabular}{|c|c|c|c|c|c|}
\hline Elementos & $\begin{array}{c}\text { Teor no XR } \\
\left(\mathrm{mg} \mathrm{kg}^{-1}\right)\end{array}$ & $\begin{array}{l}\text { Extrato do XR } \\
\quad\left(\mathrm{mg} \mathrm{L}^{-1}\right)\end{array}$ & $\begin{array}{l}\text { CONAMA }^{25} \\
\left(\mathrm{mg} \mathrm{L}^{-1}\right)\end{array}$ & $\begin{array}{c}\mathrm{LQ} \\
\left(\mathrm{mg} \mathrm{L}^{-1}\right)\end{array}$ & $\begin{array}{l}\mathrm{FM} \\
(\%)\end{array}$ \\
\hline $\mathrm{Al}$ & $8161 \pm 513$ & $0,12 \pm 0,06$ & 3,50 & 14,2 & 0,03 \\
\hline $\mathrm{Ca}$ & $7410 \pm 488$ & $264 \pm 19$ & - & 1,39 & 71,2 \\
\hline $\mathrm{Fe}$ & $29570 \pm 1922$ & $0,02 \pm 0,01$ & 2,45 & 0,15 & 0,0013 \\
\hline $\mathrm{Mg}$ & $2685 \pm 199$ & $21 \pm 0,4$ & - & 12,4 & 15,6 \\
\hline As & $\mathrm{ND}^{\mathrm{a}}$ & $\mathrm{ND}^{\mathrm{a}}$ & 0,01 & 0,41 & - \\
\hline $\mathrm{Hg}$ & $\mathrm{ND}^{\mathrm{a}}$ & $\mathrm{ND}^{\mathrm{a}}$ & 0,001 & 0,39 & - \\
\hline $\mathrm{Ba}$ & $638 \pm 50$ & $0,623 \pm 0,005$ & 0,70 & 0,03 & 1,95 \\
\hline $\mathrm{Cd}$ & $0,6 \pm 0,3$ & $<\mathrm{LQ}^{\mathrm{b}}$ & 0,005 & 0,18 & - \\
\hline Co & $<\mathrm{LQ}^{\mathrm{b}}$ & $\mathrm{ND}^{\mathrm{a}}$ & 0,07 & 0,33 & - \\
\hline $\mathrm{Cr}$ & $8 \pm 2$ & $0,09 \pm 0,01$ & 0,05 & 0,24 & 22,1 \\
\hline $\mathrm{Cu}$ & $36 \pm 3$ & $0,10 \pm 0,02$ & 2,00 & 1,07 & 5,50 \\
\hline Mn & $222 \pm 16$ & $1,72 \pm 0,06$ & 0,40 & 0,01 & 15,5 \\
\hline Mo & $12 \pm 5$ & $0,091 \pm 0,002$ & 0,07 & 1,96 & 15,2 \\
\hline $\mathrm{Ni}$ & $20 \pm 2$ & $0,178 \pm 0,002$ & 0,02 & 0,53 & 17,4 \\
\hline $\mathrm{Pb}$ & $13 \pm 5$ & $0,04 \pm 0,04$ & 0,01 & 12,3 & 6,37 \\
\hline $\mathrm{Zn}$ & $64 \pm 3$ & $0,06 \pm 0,02$ & 1,05 & 1,83 & 1,87 \\
\hline
\end{tabular}

${ }^{\mathrm{a} N D:}$ não detectado, ${ }^{\mathrm{b}} \mathrm{LQ}$ : limite de quantificação.

(Tabela 2) e menores teores dos demais elementos, mas ainda com altas concentrações de $\mathrm{Ba}$ e $\mathrm{Mn}$, dados que estão em concordância com o que foi observado por Pereira e Vitti. ${ }^{21}$ No extrato aquoso do XR foram observados maiores teores de $\mathrm{Ca}$ e $\mathrm{Mg}$ em relação aos demais elementos determinados, sugerindo a possibilidade de fornecimento desses elementos como nutrientes ao solo. A aplicação de interesse do XR é voltada para o fornecimento de nutrientes ao solo, o que, contudo, poderia ocasionar a contaminação de águas subterrâneas e, por tal motivo, os resultados obtidos dos extratos de XR foram comparados com a Resolução do CONAMA. ${ }^{25}$ De acordo com os resultados (Tabela 4), o elemento Ba apresentou uma concentração de $0,623 \mathrm{mg} \mathrm{L}^{-1}$, que é muito próxima ao limite máximo permitido em águas subterrâneas de $0,70 \mathrm{mg} \mathrm{L}^{-1}$. Os elementos $\mathrm{Cr}$, Mo, $\mathrm{Ni} \mathrm{e}$ $\mathrm{Pb}$ apresentaram resultados um pouco superiores aos respectivos limites, e o Mn apresentou uma elevada concentração no extrato, em comparação com a referida Resolução. ${ }^{25}$ Para todos os demais elementos, os resultados foram inferiores aos limites da legislação.

Foi calculada a razão entre a concentração dos elementos que foi lixiviada, com a concentração assumida como total na constituição do XR, em decorrência da digestão ácida em meio de $\mathrm{H}_{2} \mathrm{O}_{2}$ (método EPA 3050B), ${ }^{30}$ sendo adotado expressar como FM em \%. Dessa forma, com base nos resultados obtidos, foi calculado o FM de acordo com o volume utilizado para a dessorção de $40 \mathrm{~mL}$ e a massa de $2,0 \mathrm{~g}$ de $\mathrm{XR}$, conforme a equação:

$$
\mathrm{FM}=\frac{\text { Concentração elementos }(\mathrm{mg} / \mathrm{L})}{\text { Concentração elementos digestão }(\mathrm{mg} / \mathrm{kg})} \times \frac{\mathrm{v}(\mathrm{L})}{\mathrm{m}(\mathrm{kg})} \times 100
$$

Esse cálculo foi efetuado, visando verificar a potencialidade de liberação dos elementos estudados no solo e, consequentemente, de atingir águas subterrâneas. Os valores obtidos em forma de fator de mobilidade calculados indicam maior disponibilidade de Ca dentre todos os elementos. Al e Fe praticamente não são mobilizados, provavelmente porque fazem parte da matriz estrutural e não são solúveis em $\mathrm{pH}$ próximo da neutralidade. ${ }^{40}$ Assim, também, Ba e Zn estão pouco disponíveis na solução. Os elementos Mg, Mn, Mo e Ni demonstraram mobilidades semelhante (15 a 17\%), próxima do $\mathrm{Cr}$ $(22,1 \%)$, assim como o $\mathrm{Cu}$ em relação ao $\mathrm{Pb}$. O Ca demonstrou uma mobilidade de $71,2 \%$ e, sendo um macronutriente importante para o solo, tem potencial para estar biodisponível aos vegetais através da adição de XR ao solo. Com base nos valores de FM é possível inferir que os elementos mais preocupantes quanto à toxicidade para o meio foram $\mathrm{Cr}, \mathrm{Mn}, \mathrm{Ni}$ e $\mathrm{Pb}$, e assim todos os elementos foram avaliados quanto à dessorção em extratos de solo.

\section{Extratos dos solos}

Os resultados para os elementos determinados nos extratos de solos obtidos em água tipo 1 e em ácido acético são apresentados nas Figuras 1 a 3 para os elementos $\mathrm{Fe}, \mathrm{Al}, \mathrm{Ca}, \mathrm{Mg}, \mathrm{Mn}$ e Ba. Cabe informar que alguns gráficos foram omitidos, pois os valores de concentração obtidos foram inferiores ao LQ (Tabela 4), ou as concentrações foram muito inferiores aos limites permitidos pelo CONAMA, ${ }^{25}$ como no caso para os elementos $\mathrm{Zn}$ e $\mathrm{Cu}$. Os experimentos utilizando ácido acético foram conduzidos a fim de verificar a possível extração de nutrientes disponíveis para as plantas, deslocando íons metálicos ligados à matéria orgânica e às superfícies de minerais de silicatos e de óxidos de Mn, $\mathrm{Fe}$ e Al que requerem prótons para efetivar processos de troca iônica. ${ }^{41}$ Visando avaliar se havia diferenças significativas entre os valores médios das determinações, para os diferentes tratamentos com XR (Figuras 1 -3), foi empregado o critério da diferença menos significativa (DMS) para o número de réplicas $N=3$ e um nível de confiança de $95 \%$, de acordo com a literatura. ${ }^{41}$ Cabe ainda informar que para todos os extratos de solo obtidos em água pura ou em ácido acético, para ambas as profundidades investigadas, não foram observadas correlações de aumento, ou mesmo de diminuição da concentração dos elementos em função dos diferentes tratamentos efetuados (T1-T6) ou em termos do tempo decorrido, ou seja, para as três coletas (C1-C3).

\section{Alumínio e ferro}

De acordo com a Figura 1, não foi observada uma tendência de diminuição ou aumento da concentração de $\mathrm{Al}$ e Fe liberados para a 
maior profundidade estudada na extração com água, embora para o $\mathrm{Fe}$, na coleta 2 e profundidade de $5-10 \mathrm{~cm}$, as concentrações verificadas foram abaixo do LQ. Concentrações relativamente elevadas foram observadas para esses elementos nos extratos $\left(0,9 \mathrm{mg} \mathrm{L}^{-1}\right.$ para $\mathrm{Al}$ e $2,1 \mathrm{mg} \mathrm{L}^{-1}$ para $\mathrm{Fe}$ ), o que seria esperado visto que ambos são integrantes da matriz do solo, principalmente na forma de óxidos e hidróxidos, ${ }^{20,40}$ embora elevadas estimativas de desvio padrão foram constatadas, o que dificultou avaliação. Cabe informar que houve um longo período de seca que antecedeu a coleta 2 , o que poderia explicar os resultados relativamente mais elevados em alguns casos em comparação às coletas 1 e 3 . Os resultados observados para o Al, e especialmente para o Fe nos extratos obtidos em ácido acético foram relativamente inferiores em comparação com aqueles extratos obtidos em água tipo 1 , sendo que na grande maioria das determinações na profundidade de $5-10 \mathrm{~cm}$ os resultados foram inferiores ao LQ, e por isso não foram apresentados. Apesar de ser esperada uma maior lixiviação dos íons na presença de ácido acético, esse aspecto poderia estar relacionado com a interação entre o acetato com os íons, e a consequente interação com a matéria orgânica do solo. No processo de centrifugação, esses íons ficariam retidos na fase sólida, com a diminuição das concentrações na fase lixiviada. Para o $\mathrm{Al} \mathrm{e} \mathrm{Fe,}$ considerando os extratos obtidos em água tipo 1 e ácido acético, as concentrações foram inferiores àquelas estipuladas pelo CONAMA de 3,50 mg L${ }^{-1}$ e de $2,45 \mathrm{mg} \mathrm{L}^{-1}$ para $\mathrm{Al}$ e Fe, respectivamente..$^{25} \mathrm{Na}$ maioria dos extratos não foi possível verificar uma tendência de aumento nas concentrações de $\mathrm{Al}$ e Fe com o aumento das doses de XR aplicado (T2 - T4) para as diferentes coletas, o que em um primeiro momento seria esperado pelas elevadas concentrações desses elementos em comparação com os solos (Tabela 2). Todavia, o fator de mobilidade para Al e Fe foi de 0,03 e $0,0013 \%$, respectivamente, o que pode ser considerado desprezível. Por outro lado, foi observado um teor significativamente maior para amostra T5 (testemunha absoluta, sem adição de adubação de base e XR) da segunda coleta comparando com a amostra T4 que recebeu maior adição de XR. Somente para a profundidade $5-10 \mathrm{~cm}$ para primeira coleta foi verificado um teor de $\mathrm{Al}$ significativamente maior para as amostras que receberam $\mathrm{XR}$ em relação à $\mathrm{T} 5$.

\section{Cálcio e magnésio}

Foi constatada uma tendência geral de maiores concentrações de $\mathrm{Ca}$ e $\mathrm{Mg}$ (Figura 2) na camada superficial em todas as coletas, para as extrações em água, já que são íons trocáveis na matriz do solo, ${ }^{20}$ apresentando comportamento equivalente entre tratamentos e entre coletas, sem grandes variações das concentrações. Em meio ácido $\mathrm{Ca}$ e $\mathrm{Mg}$ foram detectados apenas na camada de $0-5 \mathrm{~cm}$ nas três coletas. Para a profundidade $0-5 \mathrm{~cm}$, os resultados obtidos nos extratos em ácido acético foram muito superiores em comparação com água tipo 1, em especial para o Ca. $\mathrm{O}$ íon $\mathrm{Al}^{3+}$ poderia substituir o $\mathrm{Ca}^{2+}{\mathrm{e} \mathrm{Mg}^{2+}}^{2+}$ nas intercamadas de minerais, liberando esses íons para o meio, ${ }^{42}$ e talvez por esse motivo o $\mathrm{Al}$ tenha sido determinado em menores concentrações em meio de ácido acético. Apesar disso, não foi constatada correlação entre as concentrações de $\mathrm{Ca}$ e $\mathrm{Mg}$ em função das concentrações de Al. Por outro lado, para a camada de $5-10 \mathrm{~cm}$, esses elementos apresentaram concentrações inferiores aos respectivos valores de LQ, o que sugere que a presença desses elementos em elevadas concentrações na camada superior poderia ser decorrente da presença do XR. A dessorção de $\mathrm{Mg}$ em relação ao Ca foi inferior em todas as coletas, provavelmente porque o Ca seja mais facilmente trocável do que o Mg. ${ }^{43} \mathrm{O}$ XR apresentou concentrações relativamente elevadas determinadas por XRF (Tabela 2) e nos extratos obtidos por digestão em meio ácido (Tabela 4), bem como fatores de mobilidade de $71,2 \%(\mathrm{Ca})$ e $15,6 \%(\mathrm{Mg})$, sugerindo um bom potencial para
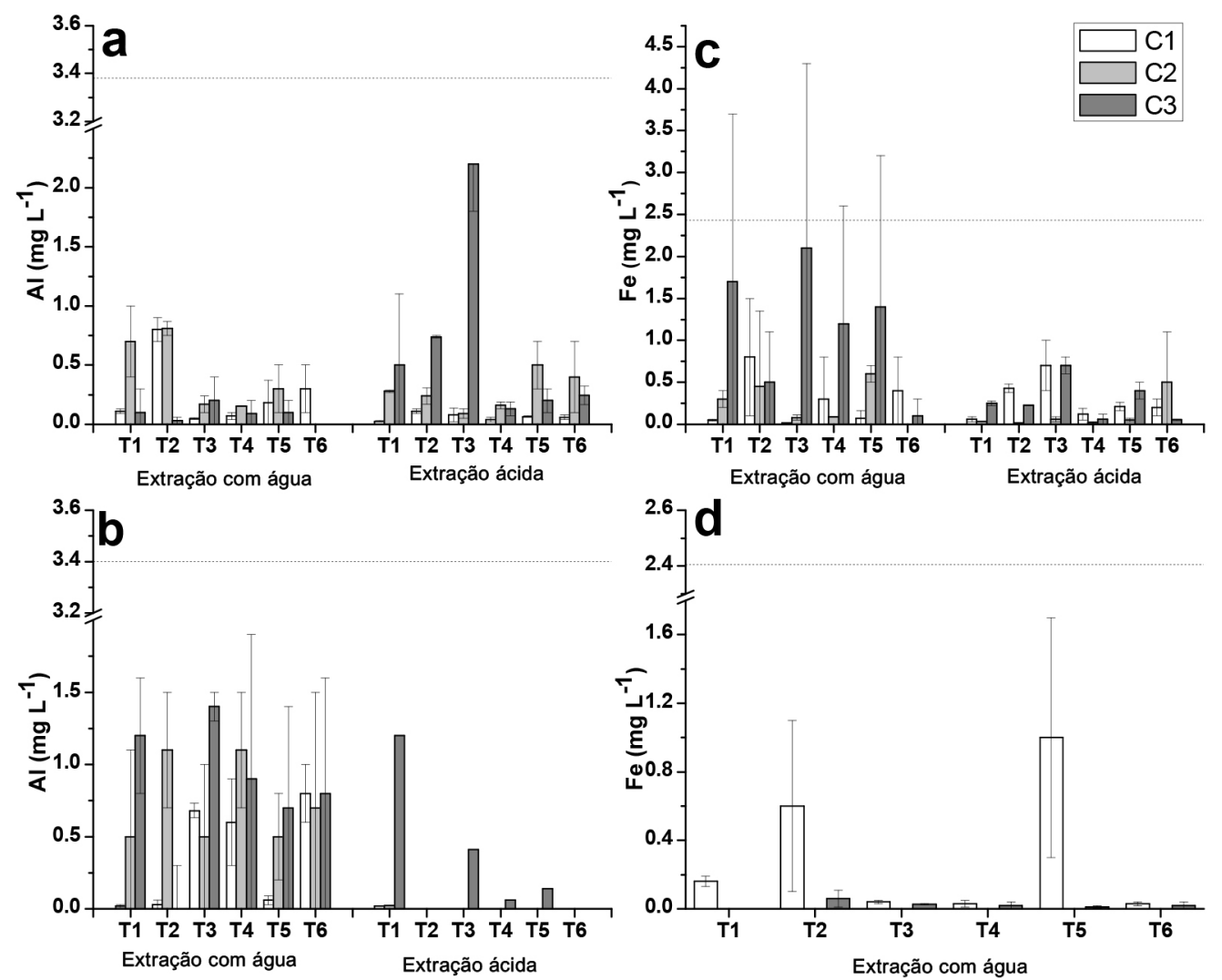

Figura 1. Concentrações de Al e Fe determinadas nos extratos aquosos e ácidos provenientes de amostras dos solos das profundidades de 0 - $5 \mathrm{~cm}$ e de 5 - 10 cm, para as coletas C1, C2 e C3. (a) Al (0 - $5 \mathrm{~cm})$; (b) Al (5-10 cm); (c) Fe $(0-5 \mathrm{~cm}) ;($ d) $\mathrm{Fe}(5-10 \mathrm{~cm})$. A linha pontilhada indica o limite estabelecido pelo CONAMA ${ }^{25}$ de acordo com a Tabela 4 
liberação desses elementos como nutrientes ao solo. Entretanto, com base nos resultados obtidos, não seria possível afirmar que a adição de $\mathrm{XR}$ ao solo poderia propiciar um ganho nos teores de $\mathrm{Ca}$ e $\mathrm{Mg}$ nos extratos, visto que os resultados não apresentaram uma tendência de aumento que possa ser considerada significativa, em decorrência dos tratamentos efetuados. Para o Ca foi observada diferença significativa entre os tratamentos somente na primeira coleta na profundidade $0-5 \mathrm{~cm}$, em que o resultado para T4 foi significativamente maior que T1 e T5 (amostras testemunhas), porém, esta diferença não foi significativa para as demais coletas. Na profundidade $5-10 \mathrm{~cm}, \mathrm{~T} 3$ e T4 apresentaram um teor de Ca significativamente maior que T1 e T5. Para o Mg os resultados para T3 e T6 foram significativamente maiores que para as outras amostras só na primeira coleta, porém, o resultado para T4 não foi significativamente maior que para $\mathrm{T} 1$ e T5. No caso do Ca com elevado FM de 71,2\%, é possível que o mesmo permaneça fortemente retido nas camadas de argilominerais, possivelmente precipitado como carbonato de cálcio. ${ }^{40}$ Apesar disso, cabe salientar que para o $\mathrm{Ca}$ e $\mathrm{Mg}$ os valores observados em meio ácido para as coletas 1 e 3 que receberam a adição de XR mostraram diferenças significativas em relação à coleta 2 , sugerindo de fato a liberação desses elementos ao solo. Isso foi constatado em meio ácido para a camada superficial, e poderia ser decorrente da solubilização de $\mathrm{CaCO}_{3}$ e $\mathrm{MgCO}_{3}$ em decorrência dos menores valores de $\mathrm{pH}$ em ácido acético em torno de 5,0, em comparação com os extratos obtidos em água tipo 1, cujos valores de $\mathrm{pH}$ se situaram entre 6,0 e 6,7.

\section{Manganês e bário}

O Mn é essencial a todos os organismos vegetais e animais, além de influenciar na solubilidade e disponibilidade de outros elementos traços no solo por estar comumente presente na forma de óxido na matriz mineral. ${ }^{44}$ Para os extratos em água tipo 1 (Figura 3 ), os resultados obtidos foram superiores na camada superficial, chegando a $66 \mu \mathrm{g} \mathrm{L}^{-1}$ (T4, coleta 1, significativamente maior que T1 e T5), embora esse valor esteja abaixo do limite máximo permitido em águas subterrâneas de $400 \mu \mathrm{g} \mathrm{L} \mathrm{L}^{-1} .{ }^{25}$ Por outro lado, na camada de $10-5 \mathrm{~cm}$, T5 apresentou um teor de Mn significativamente maior que todas as outras amostra para a primeira coleta. Foram observadas concentrações elevadas do Mn nos extratos ácidos, sendo a própria estrutura do solo a principal fonte de $\mathrm{Mn},{ }^{40}$ sugerindo uma parcial solubilização do Mn devido ao ácido acético. Este elemento foi determinado em maiores concentrações nos extratos ácidos da camada superficial do solo $(0-5 \mathrm{~cm})$. Em contrapartida, para a camada de $5-10 \mathrm{~cm}$ os valores foram relativamente baixos, ou menores que o LQ, sugerindo que as concentrações mais elevadas na camada superficial poderiam ser advindas do XR, sendo que nessa camada as concentrações de Mn excederam o limite para as coletas 1 e 3, e para T6 na coleta 2, sendo significativamente maior que os outros tratamentos, e T4 na coleta 3 foi significativamente maior que as testemunhas (T1 e T5). A solubilidade do Mn tem alta dependência com o pH. Em meio mais ácido está mais disponível, por isso foram observadas concentrações maiores deste elemento nos extratos em solução ácida, de todas as amostras da camada superficial, na qual se apresenta sorvido à superfície de minerais e em complexos com a matéria orgânica. ${ }^{44}$ Apenas uma pequena parte do Mn está biodisponível no solo, sorvido a minerais ou formando quelatos com a matéria orgânica. ${ }^{44}$ Esse é o provável motivo de sua maior concentração nos extratos das camadas superficiais dos solos estudados. Para a primeira coleta, T2 e T4 apresentaram um teor de Mn significativamente maior que as testemunhas em extratos de água na camada $0-5 \mathrm{~cm}$. Para a profundidade $5-10 \mathrm{~cm}$, T5 demonstrou um teor de Mn significativamente maior em comparação com as outras amostras para a primeira coleta em relação aos extratos em água.

$\mathrm{O}$ Ba é um dos elementos mais abundantes no solo superficial, ${ }^{45}$ e foi determinado nos extratos das amostras superficiais $(0-5 \mathrm{~cm}) \mathrm{em}$ todas as coletas, com máxima concentração de $54 \mu \mathrm{g} \mathrm{L}^{-1}$ (coleta 3, T3), em extratos de água tipo 1 (Figura 3). Nos extratos obtidos em ácido acético também foram observadas concentrações de Ba na camada superficial, porém, em valores muito superiores. Essas elevadas
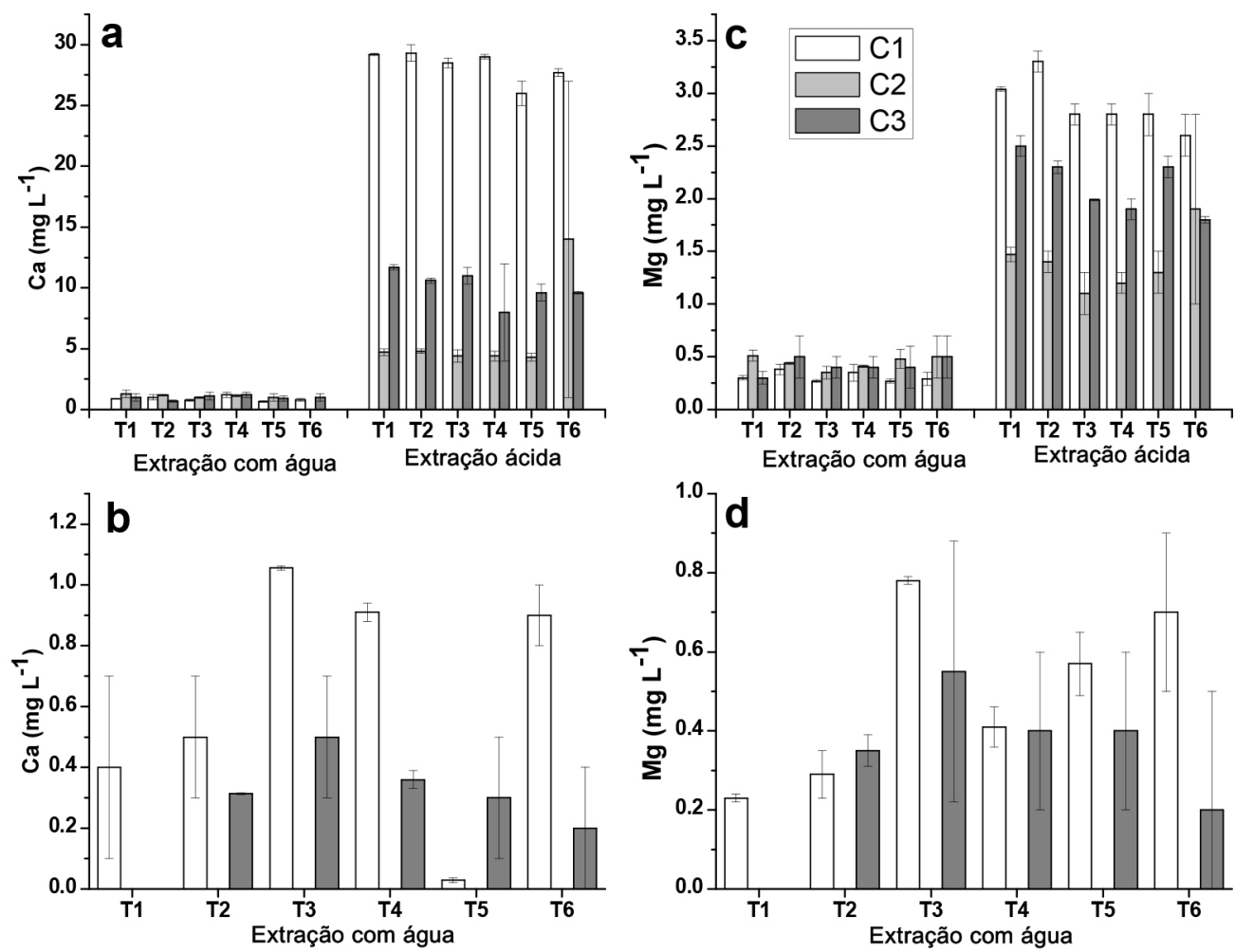

Figura 2. Concentrações de Ca e Mg determinadas nos extratos aquosos e ácidos provenientes de amostras dos solos das profundidades de 0 - $5 \mathrm{~cm}$ e de 5 - 10 $\mathrm{cm}$, para as coletas C1, C2 e C3. (a) Ca $(0-5 \mathrm{~cm}) ;($ b) $\mathrm{Ca}(5-10 \mathrm{~cm}) ;(\mathrm{c}) \mathrm{Mg}(0-5 \mathrm{~cm}) ;($ d $) \mathrm{Mg}(5-10 \mathrm{~cm})$ 
concentrações dos extratos em ácido acético podem ser devido à dissolução do $\mathrm{BaCO}_{3},{ }^{40,44}$ assim como comentado anteriormente para o $\mathrm{Ca}$ e $\mathrm{Mg}$, devido aos valores de $\mathrm{pH}$ inferiores para os extratos obtidos em ácido acético (em torno de 5,0) frente à faixa de $\mathrm{pH}$ entre 6,0 e 6,7 observada para os extratos obtidos em água tipo 1 . Isso ocasionou que em todos os extratos os limites permitidos pela legislação $\left(700 \mu \mathrm{g} \mathrm{L}^{-1}\right)^{25}$ tenham sido excedidos. Os resultados obtidos para os extratos em água tipo 1 e em ácido acético demonstraram valores mais elevados para as coletas 1 e 3, sugerindo, assim como para o Mn, que o XR contribuiu para aumentar a concentração de Ba na camada superficial, especialmente pela elevada concentração de Ba verificada na digestão do XR, (638 $\left.\mathrm{mg} \mathrm{kg}^{-1}\right)$ apesar de um valor de FM de 1,95\% (Tabela 4). Por outro lado, para todos os extratos as concentrações de Ba foram inferiores aos valores de LQ $(5-10 \mathrm{~cm})$, indicando mais uma vez que o Ba é proveniente do XR, visto que as concentrações de Ba para essa camada deveriam ser também elevadas caso o Ba fosse originário do solo, embora não tenha sido constatado um aumento significativo da concentração de Ba em função das quantidades crescentes de XR aplicado, ou superiores em relação à amostra testemunha (T5). Esse elemento tem baixa mobilidade no solo, podendo se fixar a sítios de troca em argilas e facilmente precipitado na forma de carbonato ou sulfato. Os sítios de troca catiônica apresentam seletividade para a incorporação de $\mathrm{Ba}^{2+}$ frente aos íons $\mathrm{Ca}^{2+} \mathrm{e} \mathrm{Mg}^{2+}{ }_{45,46}$ provavelmente por isso não foi detectado nos extratos de amostras na maior profundidade. Apesar de o XR em meio de ácido acético causar um aumento de $\mathrm{Ba}$ na camada superficial, o fato de não ter sido detectado Ba na camada inferior sugere não haver migração para as camadas inferiores, e em consequência esse elemento não causaria a contaminação de águas subterrâneas.

Zinco e cobre

$\mathrm{A}$ presença de $\mathrm{Zn}$ no solo está relacionada à presença de $\mathrm{Cd} \mathrm{e}$ à razão $\mathrm{Cd} / \mathrm{Zn}$, já que suas propriedades são semelhantes no solo e podem precipitar juntos. O Zn tende a inibir a biodisponibilidade de $\mathrm{Cd}$, evitando que este seja absorvido pelos vegetais, sendo os fertilizantes fosfatados considerados uma das maiores fontes de $\mathrm{Cd}$ e Zn no solo. ${ }^{44}$ As maiores concentrações de $\mathrm{Zn}$ foram obtidas nos extratos das amostras superficiais $(0-5 \mathrm{~cm})$, em especial para os extratos obtidos em meio de ácido acético. Para todos os extratos obtidos em água tipo $1(5-10 \mathrm{~cm})$, as concentrações de $\mathrm{Zn}$ foram inferiores ao LQ $\left(1,83 \mu \mathrm{g} \mathrm{L}^{-1}\right)$ assim como para a maioria dos extratos obtidos em meio de ácido acético. Nas coletas 1 e 2 a presença de $\mathrm{Zn}$ predominou nos extratos ácidos, por ser mais solúvel em condições de maior acidez. ${ }^{44}$ Considerando que houve período de estiagem, antes da coleta 2, possivelmente os íons formaram precipitados ou permaneceram sorvidos aos minerais presentes, como óxidos de $\mathrm{Al}$ e Fe. ${ }^{20,41}$ Apesar da presença de Zn no XR (Tabela 4), este não parece ter o papel principal na liberação do $\mathrm{Zn}$ para a solução do solo, em especial pelo baixo FM $(1,87 \%)$. A amostra testemunha absoluta (T5) apresentou teores similares aos observados nos solos com NPK e XR, indicando que sua presença está relacionada à formação do solo local, ${ }^{20}$ com exceção do extrato ácido para T6 coleta 2 , em que o teor de $\mathrm{Zn}$ foi significativamente maior, mas o desvio padrão relativo foi relativamente alto, e para a amostra $\mathrm{T} 4$ da terceira coleta, para a qual foi observada a maior concentração $\left(20 \pm 3 \mu \mathrm{g} \mathrm{\textrm {L } ^ { - 1 }}\right)$ em comparação com todos os tratamentos para as três coletas. Ainda assim, a concentração de $\mathrm{Zn}$ foi muito inferior ao limite máximo legislado de $1050 \mu \mathrm{g} \mathrm{L}{ }^{-1},{ }^{25}$ indicando não haver riscos de contaminação pelo $\mathrm{Zn}$ devido à aplicação do XR no solo.

As maiores concentrações de $\mathrm{Cu}$ determinadas nos extratos em água tipo 1 foram de $3 \mu \mathrm{g} \mathrm{L}{ }^{-1}$ (coleta 2, T5 e coleta 3, T3, 0-5 cm) e de $4,8 \mu \mathrm{g} \mathrm{L}^{-1}$, (coleta $1, \mathrm{~T} 3,5-10 \mathrm{~cm}$ ) sendo que para algumas amostras as concentrações de $\mathrm{Cu}$ foram inferiores ao LQ $\left(1,07 \mu \mathrm{g} \mathrm{\textrm {L } ^ { - 1 } )}\right.$ para a maior profundidade. Em meio de ácido acético as concentrações de $\mathrm{Cu}$ ficaram abaixo do LQ nos extratos de todas as amostras, para a profundidade de $5-10 \mathrm{~cm}$ e para algumas profundidades da coleta

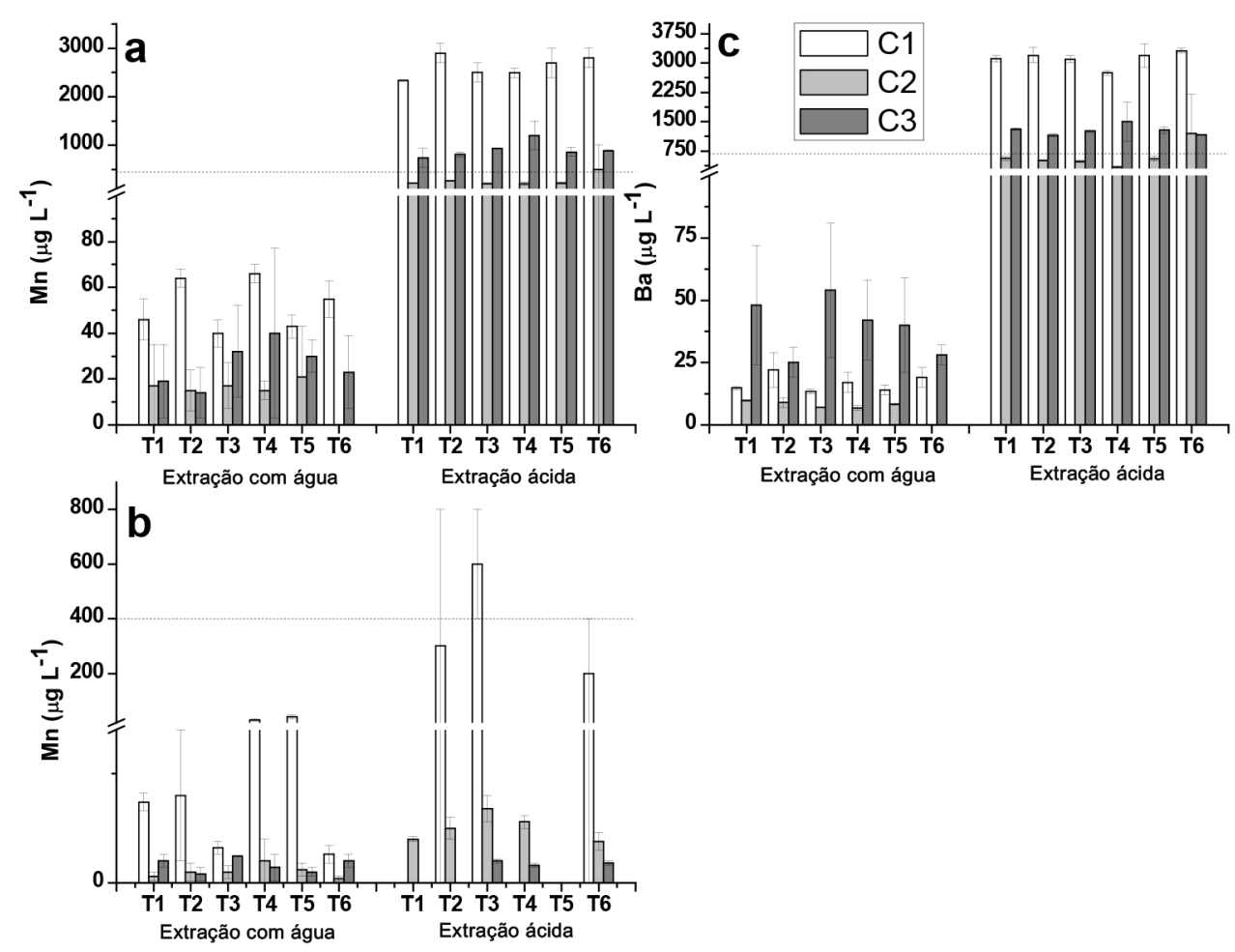

Figura 3. Concentrações de Mn e Ba determinadas nos extratos aquosos e ácidos provenientes de amostras dos solos das profundidades de 0 - 5 cm e de 5 $10 \mathrm{~cm}$, para as coletas C1, C2 e C3. (a) Mn (O - $5 \mathrm{~cm}) ;(\mathrm{b}) \mathrm{Mn}(5-10 \mathrm{~cm}) ;(\mathrm{c}) \mathrm{Ba}(0-5 \mathrm{~cm})$. A linha pontilhada indica o limite estabelecido pelo CONAMA ${ }^{25}$ de acordo com a Tabela 4 
$1(0-5 \mathrm{~cm})$. O Cu é um elemento de baixa mobilidade no solo em $\mathrm{pH}$ neutro, e o íon $\mathrm{Cu}^{2+}$ tem alta afinidade e interage fortemente com a matéria orgânica, argilas e óxidos metálicos. A maior parte do $\mathrm{Cu}$ disponível no solo está na forma complexada com a matéria orgânica nas camadas mais superficiais. ${ }^{40,46,47} \mathrm{O} \mathrm{Cu}$ pode ainda formar compostos como CuS, o que diminui sua toxicidade. ${ }^{44}$ Os resultados observados para o cobre (meio aquoso) para a profundidade de $5-10$ cm (T3 e T4) foram significativamente maiores em comparação com T1 e T5 (amostras testemunhas), ao passo que para o extrato obtido em ácido acético, o resultado observado para T4 (terceira coleta) foi significativamente maior em relação às amostras testemunhas. A maior concentração de $\mathrm{Cu}$ observada entre todos os extratos foi de $5,5 \pm 0,3 \mu \mathrm{g} \mathrm{L} \mathrm{L}^{-1}$ (coleta 2, T5), sendo, portanto, muito inferior ao valor máximo permitido de 2,00 $\mathrm{mg} \mathrm{L}^{-1},{ }^{25}$ sugerindo não haver tendência da presença do $\mathrm{Cu}$ em decorrência da adição do XR.

\section{Demais elementos}

Para o $\mathrm{Pb}$, nos extratos obtidos em água tipo 1 foram verificadas concentrações de $24 \pm 2 \mu \mathrm{g} \mathrm{L}^{-1}$ para T3 e $21 \pm 6 \mu \mathrm{g} \mathrm{L}^{-1}$ para T6 (profundidade $5-10 \mathrm{~cm}$, coleta 1 ) e para aqueles obtidos em meio de ácido acético 19,8 \pm 0,9 $\mu \mathrm{g} \mathrm{L}^{-1}$ (T2, 0-5 cm, coleta 1). Esses resultados, assim como os demais que foram inferiores ao LQ de $12,3 \mu \mathrm{g} \mathrm{L}^{-1}$ requerem certa atenção, pois o limite estabelecido pela legislação é de $10 \mu \mathrm{g} \mathrm{L}^{-1},{ }^{25}$ havendo, portanto, a possibilidade de liberação de $\mathrm{Pb}$ para o meio aquoso. Adicionalmente, o Pb está presente no XR (Tabela 4) e apresentou fator de mobilidade de $6,37 \%$, o que reforça chance de dessorção de $\mathrm{Pb}$. Apesar disso, não foi possível constatar se a presença do $\mathrm{Pb}$ nesses extratos foi decorrente do XR ou do próprio solo.

O Mo foi determinado apenas em três amostras dos extratos obtidos em ácido acético, na camada superficial, e somente na coleta 2 , com os valores de $12 \pm 5 \mu \mathrm{g} \mathrm{L}{ }^{-1}$ (T3) $6 \pm 2 \mu \mathrm{g} \mathrm{L}-1$ (T5) e $8 \pm 1 \mu \mathrm{g} \mathrm{L}^{-1}$ (T6). Para todos os demais extratos os valores foram abaixo do LQ (1,96 $\left.\mu \mathrm{g} \mathrm{L}^{-1}\right)$ e, portanto, abaixo também do valor máximo permitido de $70 \mu \mathrm{g} \mathrm{L}^{-1}$, pelo CONAMA. ${ }^{25}$

Os elementos As, $\mathrm{Cd}, \mathrm{Co}, \mathrm{Cr}, \mathrm{Hg}$ e Ni não foram detectados ou apresentaram resultados abaixo dos respectivos valores de LQ, embora $\mathrm{Cr}$ e Ni tenham sido determinados na matriz de XR, bem como o Cd, porém nesse caso o XR apresentou $0,6 \mathrm{mg} \mathrm{kg}^{-1}$ (Tabela 4). Isso sugere que o XR não contribuiria com esses elementos ao solo, ou as concentrações liberadas seriam muito baixas, e assim a aplicação de XR ao solo não seria uma fonte de contaminação significativa.

\section{CONCLUSÃO}

De acordo com o estudo realizado com extratos de solos utilizando como extratores a água tipo 1 e solução de ácido acético foi possível observar que a adição de XR ao solo visando o fornecimento de nutrientes não alterou suas propriedades, pelo menos com base nas avaliações efetuadas. Os elementos traços detectados nos extratos são provenientes do próprio solo, visto que o solo testemunha apresentou características semelhantes às observadas nos solos tratados com diferentes quantidades de XR, sendo que para a maioria dos casos, os resultados observados não diferiram significativamente em relação às amostras testemunha. Os resultados permitem inferir que o XR pode contribuir no fornecimento de $\mathrm{Ca}$ e $\mathrm{Mg}$ ao solo, especialmente o $\mathrm{Ca}$, e que de modo geral não contribuiu na lixiviação e biodisponibilidade de elementos traço indesejáveis nas amostras de solos avaliados neste experimento, como As, $\mathrm{Cd}, \mathrm{Cr}, \mathrm{Hg}$, Mo, $\mathrm{Ni}$ e $\mathrm{Pb}$, pelo menos com base nas doses de XR aplicadas. Além disso, para a maior parte dos elementos, as concentrações observadas foram inferiores àquelas estipuladas pela legislação vigente. Apesar disso, deve-se levar em consideração a possibilidade de heterogeneidade do XR em termos de diferenças de composição dos elementos estudados, o que sugere a necessidade da realização de estudos adicionais.

\section{AGRADECIMENTOS}

Os autores agradecem o suporte logístico, financeiro, e a bolsa de estudos concedida à Jeniffer V. dos Santos, ao Projeto Xisto Agrícola (Termo de Cooperação entre Embrapa Clima Temperado, PETROBRAS/SIX e FAPEG) e ao LAMIR pelas análises de fluorescência de raio $\mathrm{X}$.

\section{REFERÊNCIAS}

1. Pimentel, P. M.; Silva, C. N.; Melo, D. M. A.; Melo, M. A. F.; Maldonado, G.; Henrique, D. M.; Cerâmica 2006, 52, 194.

2. Altun, N. E.; Hiçylmaz, C.; Hwang, J. Y.; Suat Bagci, A.; Kök, M. V.; Oil Shale 2006, 23, 211.

3. dos Santos, M. M.; Matai, P. H. L. S.; R. Esc. Minas 2010, 63, 673.

4. Shirav, M.; Zimmels, Y.; Halicz, L.; Eldad, H.; Fuel 1987, 66, 281.

5. Krol, A. A., Bell, P. R. F., Greenfield, P. F.; Water Res. 1993, $2,277$.

6. Jones, D. R., Chapman, B. M., Jung, R. F.; Water Res. 1990, $24,131$.

7. Ballice, L.; Fuel Proces. Technol. 2005, 86, 673.

8. Orupõld, K.; Habicht, J.; Tenno, T.; Oil Shale 2008, 25, 267.

9. Nicolini, J.; Pereira, B. F.; Pillon, C. N.; Machado, V. G.; Lopes, W. A.; Andrade, J. B.; Mangrich, A. S.; J. Anal. Appl. Pyrolysis 2011, 90, 112.

10. Gütlein, A.; Kersten, M.; Feinstein, S.; Illner, P.; Procedia Earth Planet. Sci. 2013, 7, 413.

11. Yen, T. F.; Chilingarian, G. V.; Oil shale. Elsevier: Amsterdan, 1976.

12. Snape, C.; Composition, Geochemistry and Conversion of Oil Shales. Springer: UK, 1993.

13. Speight, J. G.; Shale oil production processes. Elsevier: USA, 2012.

14. Bell, P. R. F.; Krol, A. A.; Greenfield, P. F.; Water Res. 1986, $20,741$.

15. Jaber, J. O.; Probert, S. D.; Appl. Energy 1999, 62, 169.

16. Ibrahim, K. M.; Jaber, J. O.; Environ. Geol. 2007, 52, 979.

17. Zhang, L.; Zhang, X.; Li, S.; Wang, Q.; Energy Procedia 2012, 17, 39.

18. Bohn, H. L.; Mcneal, D. L.; O'connor, G. A.; Soil Chemistry, $3^{\text {rd }}$ ed., John Wiley \& Sons: New York, 2001.

19. Sparks, D. L.; Environmental Soil Chemistry. Academic Press, $2^{\text {nd }}$ ed., Elsevier Science, 2003.

20. Sposito, G.; The chemistry of soils, $2^{\text {nd }}$ ed., Oxford University Press: New York, 2008.

21. Pereira, H. S., Vitti, G. C.; Hortic. Bras. 2004, 2, 317.

22. Leão, R. E.; Giacomini, S. J.; Redin, M.; Souza, E. L.; Silveira, C. A. P.; Pesq. Agropec. Bras. 2014, 49, 818.

23. Doumer, M. E.; Giacomini, S. J.; Silveira, C. A. P.; Weiler, D. A.; Bastos, L. M.; Freitas, L. L.; Pesq. Agropec. Bras. 2011, 46, 1538.

24. Adamson, J.; Irha, N.; Adamson, K.; Steiness, E.; Kirso, U.; Oil Shale 2010, 27, 250.

25. Conama; Resolução $n^{\circ}$ 420, 28 de dezembro de 2009.

26. Embrapa; Sistema Brasileiro de Classificação de Solos. Embrapa SPI: Rio de Janeiro, 2009.

27. DIN 38414-4: German Standard Methods for the Examination of Water, Waste Water and Sludge; Sludge and Sediments (Group S). Determination of Leachability by Water (S4), 1984.

28. Delay, M., Lager, T., Schulz, H. D., Frimmel, F. H.; Waste Manage. 2007, 27, 248.

29. ABNT NBR 10005, Procedimento para obtenção de extrato lixiviado de resíduos sólidos, 2004.

30. EPA. Method 3050b, Acid digestion of sediments, sludges, and soils, 1996.

31. dos Santos, V. C. G.; Grassi, M. T.; Campos, M. S.; Peralta-Zamora, P. G.; Abate, G.; Analyst 2012, 137, 4458. 
32. Shi, J.; Tang, Z.; Jin, Z.; Chi, Q.; He, B.; Jiang, G.; Anal. Chim. Acta 2003, 477, 139.

33. Bhargava, S.; Awaja, F.; Subasinghe, N. D.; Fuel 2005, 84, 707.

34. Nayak, P. S.; Singh, B. K.; Bull. Mater. Sci. 2007, 30, 235.

35. Chaves, L. H. G.; Vasconcelos, A. C. F.; Revista Brasileira de Engenharia Agrícola e Ambiental 2006, 10, 84 .

36. Van Raij, B.; Andrade, J. C.; Cantarella, H.; Quaggio, J. A.; Análise Química para Avaliação da Fertilidade de Solos Tropicais, Campinas, Instituto Agronômico, 2001.

37. INMETRO. DOQ-CGCRE-008. Orientação sobre validação de métodos analíticos, $4^{\mathrm{a}}$ revisão 2011.

38. Skoog, D. A.; West, D. M.; Holler, F. J.; Crouch, S. R.; Fundamentos de Química Analítica, trad. 9a ed. norte-americana, São Paulo, 2014

39. Maranhão, T. A.; Silva, J. S. A.; Andrade, R. M.; Bascuñan, V. L. A. F.; Oliveira, F. J. S.; Curtius, A. J.; Microchem. J. 2013, 106, 139.

40. McBride, M. B.; Environmental Chemistry of Soils, Oxford University Press: New York, 1994.
41. Amaral Sobrinho, N. M. B.; Barra, C. M.; Lã, O. R.; Em Química e Mineralogia do Solo - Parte II - Aplicações; Alleoni, L. R. F., Melo, V. de F., eds.; SBCS: Viçosa, 2009, cap XVI.

42. White, R. E.; Princípios e práticas da ciência do solo, $4^{\mathrm{a}}$ ed., Andrei, São Paulo, 2009.

43. Osman, K. T.; Soils: principles, properties and management, Springer: New York, 2013.

44. Hooda, P. S.; Trace elements in soil, Wiley: United Kingdom, 2010.

45. Alloway, B. J.; Heavy metals in soils: Trace Metals and Metalloids in Soils and their Bioavailability, $3^{\text {rd }}$ ed., Springer: UK, 2013.

46. Andrade, M. G.; Tese de Doutorado, Universidade Estadual Paulista, Brasil, 2011.

47. Foth, H. D.; Fundamentals of Soil science, $8^{\text {nd }}$ ed., John Wiley \& Sons: New York, 1990. 